\title{
Non-Destructive examination of underground pressure vessels using acoustic emission (AE) techniques ${ }^{\S}$
}

\section{Deniz Karaduman', Durmuş Ali Bircan², Ahmet Çetin ${ }^{3}$}

\author{
1,2,3 Çukurova University, Department of Mechanical Engineering, 01330 Balcalı, Adana, TURKEY
}

\begin{abstract}
The methodology of Acoustic Emission (AE) for detecting and monitoring damages, cracks and leaks in different structures is widely used and has earned a reputation recently as one of the most reliable and wellestablished technique in Non-Destructive Testing (NDT). Besides evaluation of fracture behavior, crack propagation and fatigue detection in metals, composites, wood, fiberglass, ceramics and plastics; it can also be used for detecting faults and pressure leaks in pressure vessels, tanks and pipes.

As a relatively "clean" form of energy, Liquefied Petroleum Gas (LPG) is widely used for industrial applications and domestic heating. Periodic inspection of buried tanks used for LPG storage is complicated and limited because of their underground location. This situation prevents "conventional" NDT techniques from being used. So, AE testing which fulfills all safety requirements, is the most appropriate and cost-effective technique that can be used for periodic inspection and proof testing.

In addition of a general presentation on the $\mathrm{AE}$ technology and its applications, this study provides comprehensive evaluation of AE testing techniques of underground LPG tanks during service in accordance with TS EN standards. Some representative results and data obtained from a performed AE test are also provided.
\end{abstract}

Keywords: Acoustic Emission (AE), Non-Destructive Testing (NDT), Underground LPG Tanks, In-Service Monitoring.

\section{INTRODUCTION}

Acoustic Emission (AE) is defined as a phenomenon, where one or more local sources in materials, which are under stress, are emitting energy and producing temporary elastic waves. AE covers a broad range in material science, construction and process development. The largest events which can be analyzed by $\mathrm{AE}$ are seismic occurrences, the smallest are dislocations occurring in metals by load. Between these two, there is a broad range of detailed research work and industrial application [1]. One of those application area is the inspection of buried LPG tanks of industrial plants and some domestic buildings.

AE Testing (AET) has become a recognized NDT method commonly used to detect and locate faults in mechanically loaded structures and components. AE can provide comprehensive information on the origination of a discontinuity (flaw) in a stressed component and also provides information pertaining to the development of this flaw as the component is subjected to continuous or repetitive stress [2].

Huge quantities of LPG tanks have been installed in Turkey during the last decade. For the vast majority of those tanks are located under the ground because of the safety considerations. Since inspection is obligated by national legislations of occupational health and safety, after ten years of operation huge numbers of tanks are now set for inspection. Traditional methods of inspection require that the tank is unearthed, which means that they are cumbersome, slow and expensive, i.e. very cost-ineffective [2]. Thus, NDT techniques of AE are preferred for periodic inspection and proof testing of those tanks.

This procedure is currently being validated via experimental tests on a large number of LPG tanks by comparing the results with those obtained by conventional NDT techniques. Initial results appear to confirm the effectiveness of the technique and encourage further research in this field [3].

The European Standards TS EN 12817 [4] (comprised of LPG Tanks up to $13 \mathrm{~m}^{3}$ ), TS EN 12819 [5] (comprised of LPG Tanks greater than $13 \mathrm{~m}^{3}$ ) and TS EN 14584 [6] allows AE-based techniques to be used in periodic inspection and the requalification of underground LPG tanks. The main objective of this study was to present general information

\footnotetext{
${ }^{*}$ Corresponding authour

Email: ahmetcetin@cu.edu.tr (A. Çetin)

$\S$ This paper was presented at the IMSEC-2016
} 
about AE technology and its applications, to provide comprehensive analysis of AE testing techniques of underground LPG tanks during service and to review the results and the outcoming data obtained from a performed AE inspection of an underground LPG tank belonging to a domestic building with a capacity of $5 \mathrm{~m}^{3}$.

\section{OVERWIEV ON AE TESTING TECHNIQUE}

\subsection{Principles of AE Testing}

AE testing refers to a technique of testing, recording and analyzing AE signals using apparatus as well as speculating on the status of an AE source as normal or not based on AE signals. The elastic waves sent from the AE source are transmitted to the material surface via a transmission media and converted to electric signals by sensors before being magnified, processed and recorded. Through the analysis and processing of acquired signals, any defects inside the material could be detected [7] as illustrated in Figure 1.

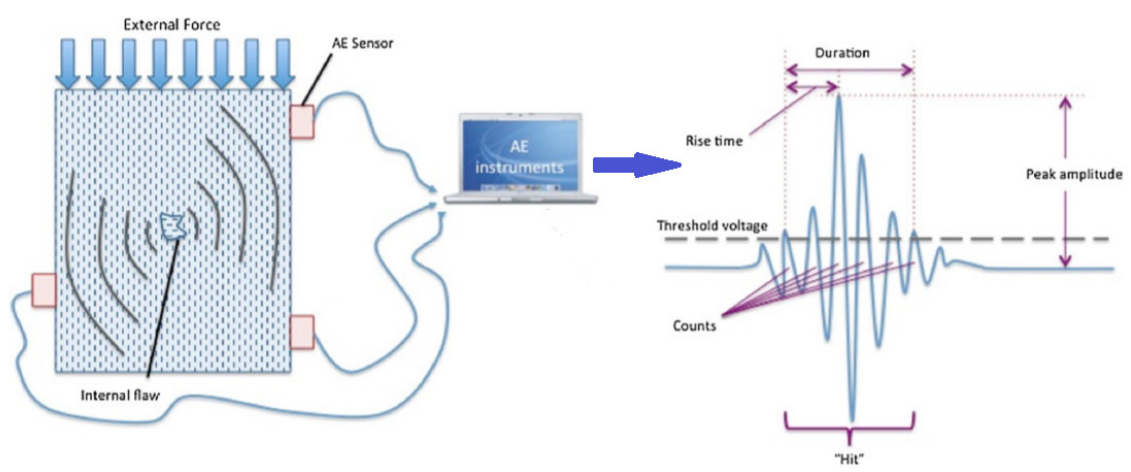

Figure 1: Principle of AET. [8]

The diagram illustrates various parameter defined below:

- Count: The number of times a peak in the wave lies above a set threshold frequency.

- Hit/Event: A collective term for a group of AE counts that lie above the threshold amplitude. A hit is also defined as a signal that triggers the system channel to accumulate data.

- Rise time: The time between a wave triggering above the threshold amplitude and the time of the peak amplitude of that wave. The rise time is related to the source-time function and can describe the type of fracture or eliminate noise signals.

- Duration: The time between an AE waveform triggering above the threshold and its disappearance below that threshold. The duration is related to the source magnitude and noise filtering.

- Amplitude: The peak voltage of a waveform. It is closely related to the magnitude of the source event [8].

- MARSE (Measured Area Under the Rectified Signal Envelope): It is derived from the rectified voltage signal over the duration of the AE waveform with voltage-time units and it is strongly sensitive to amplitude and duration [9].

The technology involves the use of ultrasonic sensors $(20 \mathrm{Khz}-1 \mathrm{Mhz}$ ) that listen for the sounds of material and structural failure. AE frequencies are usually in the range of $150-300 \mathrm{kHz}$, which is above the frequency of audible sound. Crack growth due to hydrogen embrittlement, fatigue, stress corrosion, and creep can be detected and located with the use of this technology. High-pressure leaks can also be detected and isolated [2].

When considering detecting an AE waveform, one must decide on the type of sensor, pre-amplification and band-pass filters. Typical sensors used in AET are piezoelectric in nature, which convert mechanical strain of the piezo element into an electric signal [10]. Another important consideration is how to attach the sensor to the material as well as the location of multiple sensors.

AE signals are very weak and must be amplified around 100 times in order to allow detection. Finally, to reduce background noise from interfering with AE signal interpretation, a band-pass filter is included into the system. Calibration of the system can be achieved in several ways; however, the commonest is the use of Hsu-Nielsen method as known as 
Pencil Lead Break (PLB) tests [11]. Components of a typical AE instruments are illustrated schematically in Figure 2.

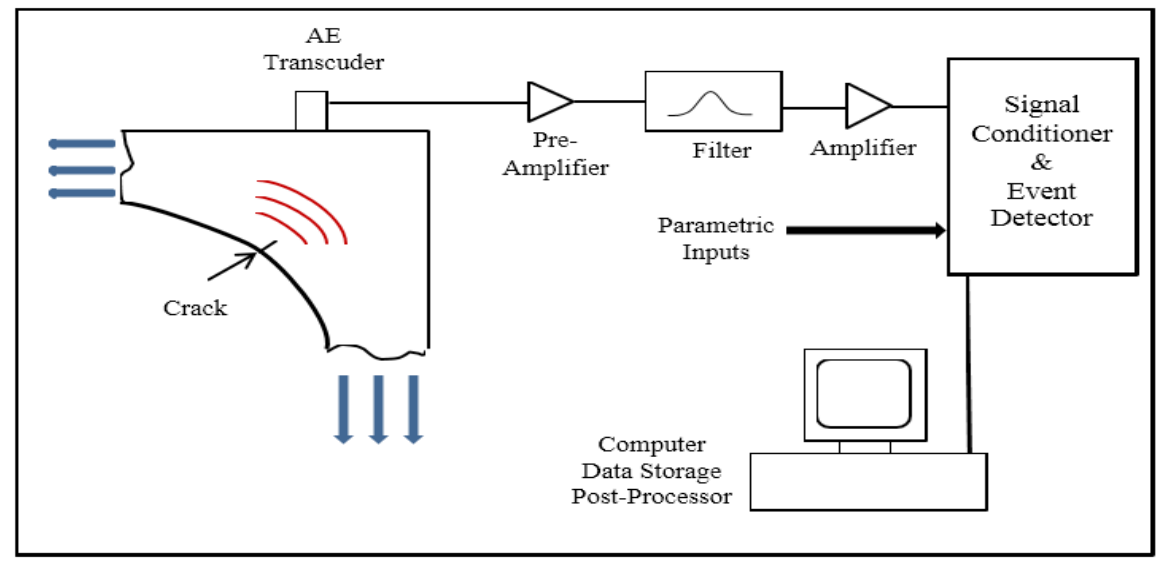

Figure 2: A typical AE system setup [12]

\subsection{Applications of AE Testing}

As laboratory work; it's a very effective instrument in the field of material examining and observation of deformation and fracture behavior. During the manufacturing process; it's used in appearance design phase like thermos-compression bonding and shaft straightening, observation of welding and wood drying process and corrosion testing. As a structural inspection method; it's very satisfactory about determination of flaw, crack, leakage, corrosion and welding failure in pressure vessels, storage tanks, pipelines, airplane and airspace vehicles, bridges, railways, etc. Besides of those determinations, AE techniques can localize the failure area. AET applications of pressure vessels, pipelines, storage tanks and bridges are illustrated in Figure 3.
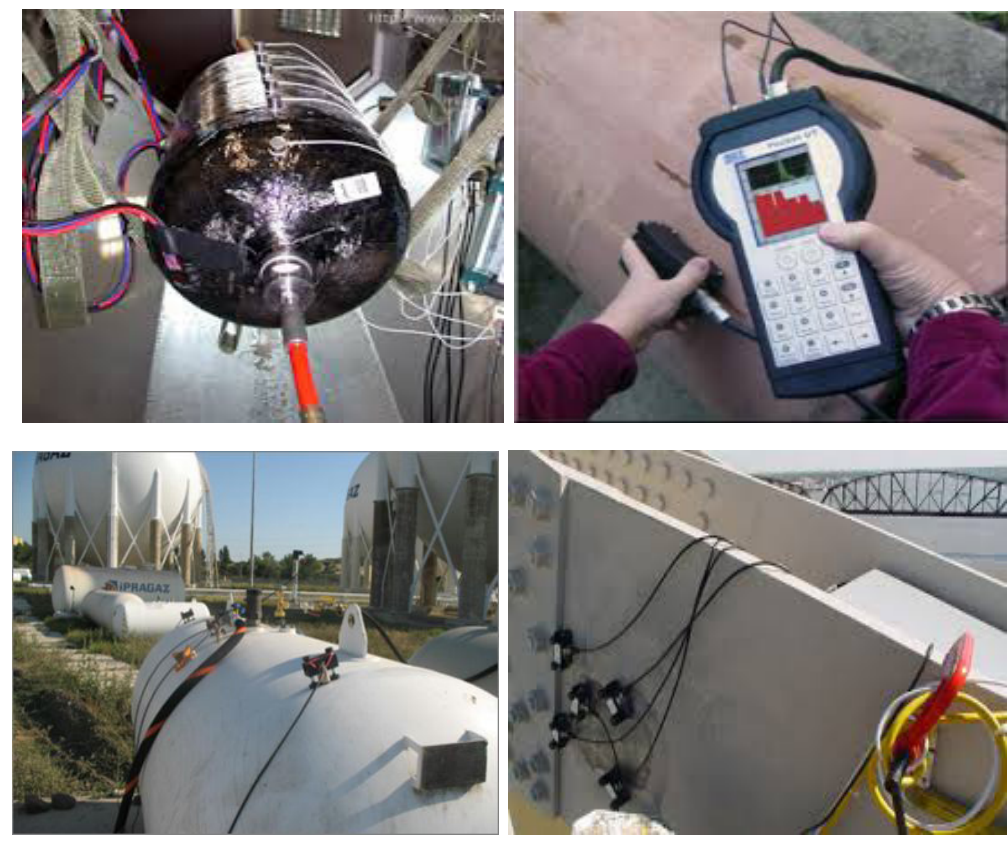

Figure 3: Examples for AET application [13, 14, 15, and 16].

\section{EXPERIMENTAL SET-UP}

\subsection{Installation of Testing Equipment}

On-site inspection has been performed using a mobile laboratory, equipped with a LPG pressurization device, MISTRAS Micro-II Digital AE System processor and other instruments for AE testing. Tests have been performed on a tank designed and manufactured to operate in an underground location with "horizontal" position. The storage tank with a capacity of $5 \mathrm{~m}^{3}$ has a cylindrical geometry $(1200 \mathrm{~mm}$ outer diameter, $7 \mathrm{~mm}$ shell thickness and $4050 \mathrm{~mm}$ length) and is closed by hemispherical ends at both sides. The operating temperature is between $-10^{\circ} \%+40^{\circ} \mathrm{C}$ and operating pressure is 15 bar. Real time pressure measurements have been performed using a manometer shown in Figure 4 (ECO1 Di- 
gital Ex-proof Manometer) directly connected to the gas pipeline near the tank. Because of the limited accessible area and the presence of components (valves, pipes and other accessories), only two piezoelectric sensors shown in Figure 4 (KRNI150 100kHz-400kHz) could be positioned on the tank surface by using magnetic connection apparatus, with a mutual distance of $400 \mathrm{~mm}$, shorter than determined maximum allowed sensor spacing according to TS 11634 [18] and TS 15495 [19].

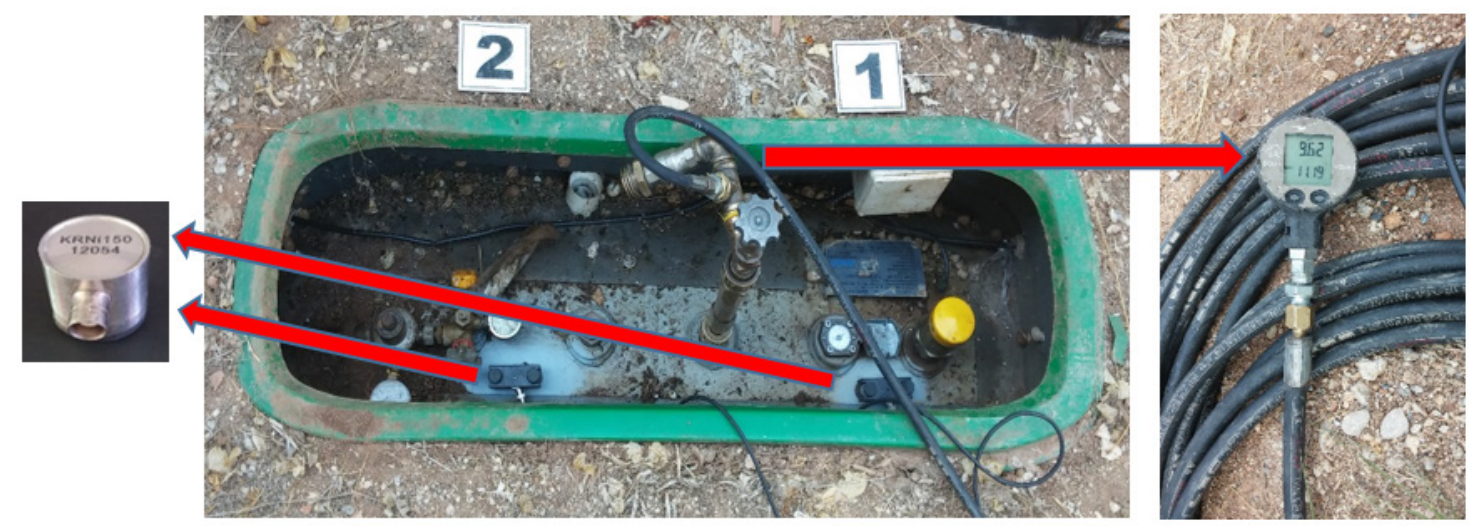

Figure 4: $\mathrm{AE}$ sensor mounted on the tank surface and manometer connected to the gas pipeline.

Sensors, cables and preamplifiers have all been successfully tested for compliance with existing standard requirements [20-22]. Calibrations of the piezoelectric sensors are performed by using "Hsu-Nielsen" method as known as PLB method. This procedure is very crucial in order to define the senility of the sensors. Any inaccuracy of the coupling of the sensors could lead to obtain faulty data. "Hsu-Nielsen" method is shown in Figure 5 both schematically and visually.
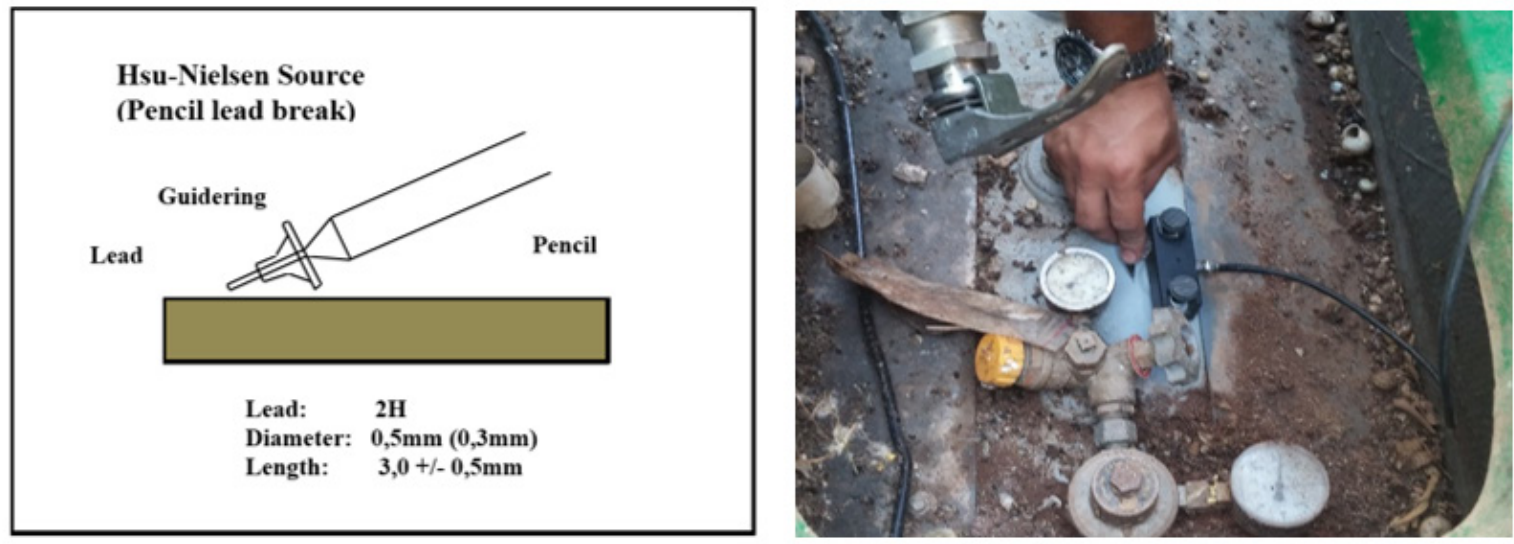

Figure 4: Illustrations of Hsu-Nielsen method (PLB).

After detecting the background noise value $\left(\mathrm{dB}_{\mathrm{AE}}\right)$, threshold value is set to $45 \mathrm{~dB}_{\mathrm{AE}}$ to avoid environmental ambiguities. Calculation of evaluation threshold is shown in Figure 5 and in Table 2.

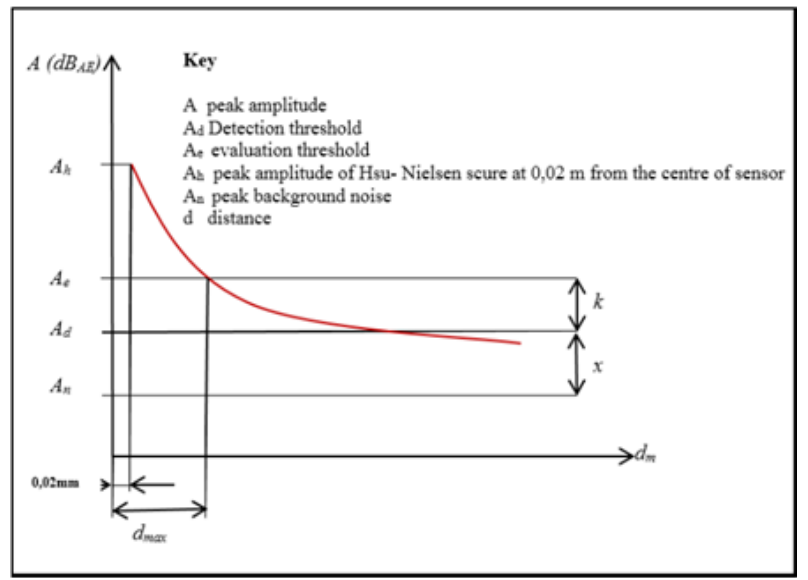

Figure 5: Determination of the maximum sensor spacing from attenuation curve. [6] 
Table 2. Calculation of evaluation threshold.

\begin{tabular}{|c|c|c|}
\hline \multicolumn{2}{|c|}{ Key } & $\mathrm{dB}_{\mathrm{AE}}$ \\
\hline $\mathrm{A}_{\mathrm{n}}$ & Peak background noise & 21 \\
\hline $\mathrm{A}_{\mathrm{d}}$ & Detection threshold $\left(\mathrm{A}_{\mathrm{n}}+\mathrm{X} ; \mathrm{X}=12 \mathrm{~dB}\right)$ & 33 \\
\hline $\mathrm{A}_{c}$ & Evaluation threshold $\left(\mathrm{A}_{\mathrm{d}}+\mathrm{K} ; \mathrm{K}=12 \mathrm{~dB}\right)$ & 45 \\
\hline
\end{tabular}

\subsection{Pressurization and Data Acquisition}

The pressure equipment was monitored prior to pressurization for $10 \mathrm{~min}$ at the detection threshold, to confirm that there is no ambient noise, which might interfere with the test. To avoid noises caused by turbulence, as recommended by existing standard procedures [23], the pressurization device has allowed a pressure gradient $\approx 0.3 \mathrm{bar} / \mathrm{min}$ to be held throughout the test.

When reached at the desired pressure level, it's waited at least $5 \mathrm{~min}$ at every pressure grade. At the top pressure level, pressurization has been stopped and stabilized at least $10 \mathrm{~min}$. During these process, LPG is used as the pressurization item. Pressure sequence and loading is calculated as the \%50, \%85 and \%110 capacity of tank operation pressure. At every stage of desired pressurization, storage tank was monitored by sensors with a period of 5 min. The sequence of pressurization of this tank was shown in Figure 6.

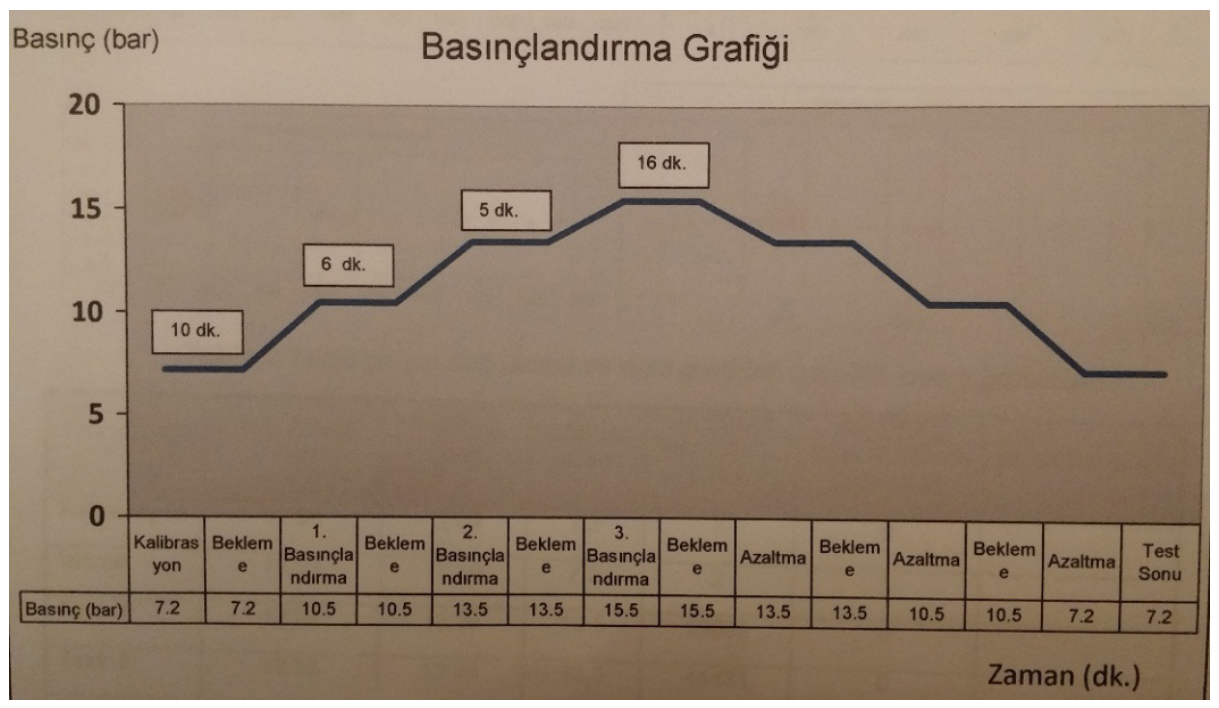

Figure 6: The sequence of pressurization of the tank.

\subsection{Data Acquisition}

Data acquisition and processing is performed using MISTRAS Micro-II Digital AE System with "AEwin for SAMOS" software packet. Data graphs of testing obtained via AE system and test parameters were illustrated in Figure 7 and Table 3.

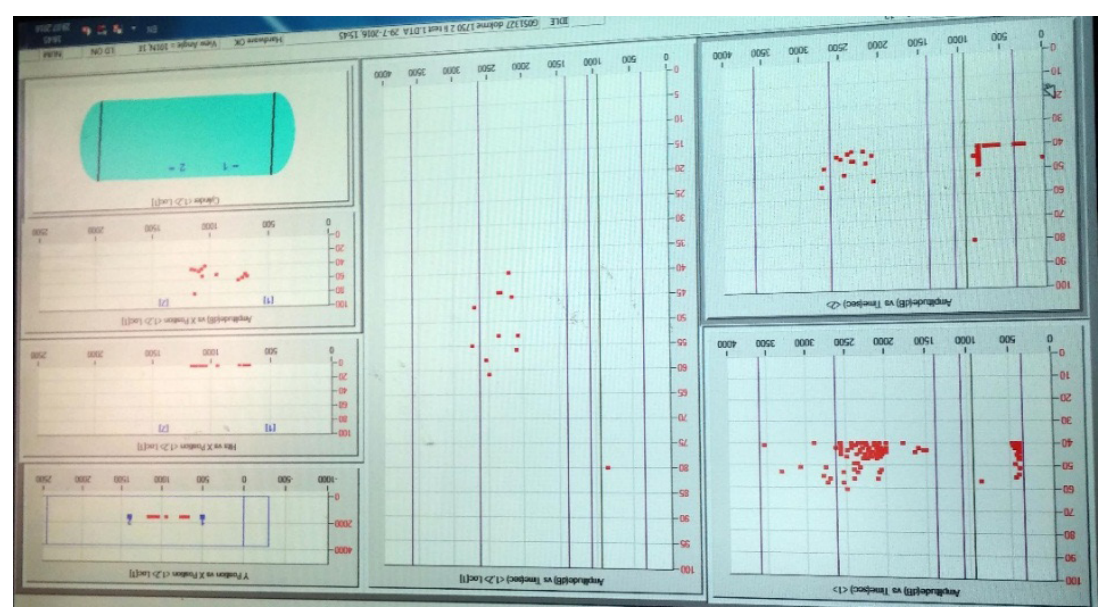

Figure 7: Verification and data graphs of the test (Screen View). 
Table 3. Test Parameters.

\begin{tabular}{|c|c|c|c|c|c|}
\hline Test Step & $\begin{array}{c}\text { Start } \\
\text { Time }\end{array}$ & $\begin{array}{c}\text { Finish } \\
\text { Time }\end{array}$ & $\begin{array}{c}\text { Pressure } \\
\text { (Bar) }\end{array}$ & $\begin{array}{c}\text { AE Hits } \\
\text { (Total) }\end{array}$ & $\begin{array}{c}\text { AE Events } \\
\text { (Total) }\end{array}$ \\
\hline Calibration & $15: 41$ & $15: 43$ & 9,85 & 64 & 1 \\
\hline Background Noise Observation & $15: 43$ & $15: 53$ & 9,85 & 27 & 0 \\
\hline $1^{\text {st }}$ Pressurization & $15: 53$ & $16: 08$ & 11 & 866 & 1 \\
\hline Test & $16: 08$ & $16: 13$ & 11 & 866 & 1 \\
\hline $2^{\text {nd }}$ Pressurization & $16: 13$ & $16: 34$ & 15,5 & 960 & 10 \\
\hline Test & $16: 34$ & $16: 49$ & 15,5 & 970 & 12 \\
\hline
\end{tabular}

\section{INTERPRETATIONS OF TESTING RESULTS}

\subsection{Grading Criteria and Real-time Control}

The grading criteria are used for real time control and for subsequent source severity classification. They shall be defined by the $\mathrm{AE}$ test organisation on the basis of experience. Real-time control parameters are given in Table 4 below.

Table 4. Example of definition of real-time control parameters [6].

\begin{tabular}{|c|c|}
\hline Real-time Control Parameters & Values \\
\hline $\mathrm{EB}$ & 1000 \\
\hline $\mathrm{A} 1$ & $105 \mathrm{~dB}_{\mathrm{AE}}$ \\
\hline $\mathrm{N} 1$ & 5 \\
\hline $\mathrm{AC} 1$ & $100 \mathrm{~dB}_{\mathrm{AE}}$ \\
\hline $\mathrm{NC} 1$ & 5 \\
\hline $\mathrm{AC} 2$ & $88 \mathrm{~dB}_{\mathrm{AE}}$ \\
\hline $\mathrm{NC} 2$ & 20 \\
\hline $\mathrm{N} 3$ & 2 \\
\hline $\mathrm{Z}$ & $0,1 \mathrm{~d}_{\max , \mathrm{u}}$ \\
\hline $\mathrm{t}_{\mathrm{h}}$ & $5 \mathrm{~min}$ \\
\hline
\end{tabular}

The values in the table are an example only and under no circumstances should these example values be used. Grading criterias are;

- the number N1 of located burst signals with a distance corrected peak amplitude above a "high" specified value A1;

- the occurrence of a number N3 of located burst signals above the specified corrected peak amplitude AC2 in a defined time period " $\mathrm{t}_{\mathrm{h}}$ " during the hold. The time period " $\mathrm{h}_{\mathrm{h}}$ " starts 2 min after the beginning of the hold period.

- the number $\mathrm{NC1}$ of located burst signals with a distance corrected peak amplitude above a "high cluster" specified value $\mathrm{AC1}$ within a square of an edge length or circle with a diameter of $\mathrm{Z}$.

- the number NC2 of located burst signals with a distance corrected peak amplitude above a "low cluster" specified value AC2 within a square of an edge length or circle with a diameter of $Z[6]$.

\subsection{AE Source Location Cluster Severity Grading and Test Results}

The AE source location clusters shall be graded according to their AE activity and intensity into 3 grades (see Table 5) based upon EN 13554 [20].

Table 5. Source severity grading [20].

\begin{tabular}{|c|c|c|}
\hline $\begin{array}{c}\text { Source severity } \\
\text { grading }\end{array}$ & Definition & Further actions \\
\hline 1 & minor source & no further actions shall be necessary; included in the report for comparison with subsequent \\
\hline 2 & active source & $\begin{array}{c}\text { further NDT shall be recommended if the source is associated with specific parts of the pressu- } \\
\text { re equipment (e.g. weld seams, attachments, etc.) }\end{array}$ \\
\hline 3 & $\begin{array}{c}\text { very active } \\
\text { source }\end{array}$ & $\begin{array}{c}\text { Further evaluation by other appropriate NDT shall be carried out before the pressure equip- } \\
\text { ment goes into service }\end{array}$ \\
\hline
\end{tabular}


The real-time control parameters and the grading of the tank subjected to AET are shown in Table 6 below. During the test $12 \mathrm{AE}$ event has been detected. 11 of those detections are between $40-60 \mathrm{~dB}_{\mathrm{AE}}$ range. Only one detected $\mathrm{AE}$ event (maximum detection) with a value of $80 \mathrm{~dB}_{\mathrm{AE}}$ is also below the values of $\mathrm{A} 1, \mathrm{AC} 1$ and $\mathrm{AC}$. Thus, the LPG tank subjected to AET is graded as "Class-1" with minor source.

Table 6. Tank Classification.

\begin{tabular}{|c|c|c|c|c|c|}
\hline $\begin{array}{c}\text { Maximum Event } \\
\text { Frequency }\end{array}$ & \multirow{3}{*}{12} & & Standard Value & Measured Value & Tank Class \\
\cline { 3 - 5 } & \multirow{4}{*}{} & N1 & 5 & 0 & CLASS-1 \\
\cline { 3 - 5 } & & NC1 & 5 & 0 & \\
\cline { 3 - 5 } & & NC2 & 20 & 0 & \\
\cline { 2 - 5 } & & N3 & 2 & 0 & \\
\hline
\end{tabular}

\section{CONCLUSION}

An AE-based inspection of underground LPG tanks has been proposed to perform quick and cost-effective experiments. But in some cases, experimental set-up should have some limitations due to small and crowded accessible area on the tank. In this examination, only two sensors was used. Despite of those limitations, AE based inspection of the tank has been performed successfully. This method also increases the safety of the operators involved in the test and protects natural resources and the environment (no disposal of residuals necessary, no cleaning and no draining of contaminated water, etc.).

As a result, inspections based on $\mathrm{AE}$ proves to a technologically advanced and reliable technique that reduces downtime and inspection costs of the tank. Additionally, the method illustrated in this study has a potential and widely applicable field for other industrial instruments and furthermore studies could be prompted.

\section{ACKNOWLEDGEMENTS}

This study is supported by Çukurova University Research Fund [FYL-2016-6515].

\section{REFERENCES}

[1] Tuncel S., (2008), "Latest Developments in The Field of NDT Technologies: Acoustic Emission", 3rd International Non-Destructive Testing” Symposium and Exhibition, Istanbul Turkey, April 2008.

[2] Hellier C. J., (2003), "Handbook of Nondestructive Evaluation”, vol.70, pp.466-470.

[3] Petrisa C. D., Siteb C.D., Lenzunic P., Mazzocchib V., Mennutia C., (2004), "An Innovative AE Technique For The Verification of Underground and Buried Pressure Equipment", ICEM12- 12th International Conference on Experimental Mechanics, Politecnico di Bari, Italy

[4] Turkish Standard TS EN 12817, (2010), "LPG Equipment and Accessories - Inspection and Requalification of LPG tanks up to and including $13 \mathrm{~m}^{3}$, ICS 23.020 .30 .

[5] Turkish Standard TS EN 12819, (2009), "LPG equipment and accessories - Inspection and requalification of LPG tanks greater than $13 \mathrm{~m}^{3}$ ", ICS 23.020.30.

[6] Turkish Standard TS EN 14584, (2013), "Non-destructive testing - Acoustic emission testing- Examination of metallic pressure equipment during proof testing - Planar location of AE sources”, ICS 17.140.20\&77.040.20.

[7] Gao L., Zai F., Su F., Wang H., Chen P. and Liu L. (2011), "Study and Application of Acoustic Emission Testing in Fault Diagnosis of Low-Speed Heavy-Duty Gears”, Sensors (Basel). 11(1), pp.599-611.

[8] Rashid M.S. and Pullin R., (2014), "The Sound of Orthopaedic Surgery - The Application of Acoustic Emission Technology in Orthopaedic Surgery: A Review”, Eur J. Orthop. Surg. Traumatol 24:1-6.

[9] Safari A., (2006), "Acoustic Emission Analysis of the Effect of a 2D Wedge Shaped Blade on the Compact Bone Cutting Process", Department of Mechanical and Electronic Engineering School of Engineering Institute of Technology Sligo.

[10] Muravin B (2009), "Acoustic Emission Science and Technology”, J Build Infrastruct Eng Israeli Assoc. Eng. Archit Israel.

[11] Nielson A (1980), “Acoustic Emission Source Based on Pencil Lead Breaking”, Report 80-15, Danish Welding Institute.

[12] Huang M.,Jiang L., Liaw P.K., Brooks C.R., Seeley R., and Klarstrom D.L., (2009),” Using Acoustic Emission in Fatigue and Fracture", Materials Research, Nondestructive Evaluation: Overview, University of Tennessee.

[13] Federal Institute for Materials Research and Testing (2008), "Evaluation of Composite Cylinders Using Acoustic Emission”, Hydrogen Storage Systems for Automotive Application. Acoustic

[14] Emission Instrumentations, http://iti.northwestern.edu. 
[15] Akustik Emisyon, http://www.tr-tuv.com.tr.

[16] McCormick R.R., (2007), “Advancements In Acoustic Emission Testing Of Steel Highway Bridges”, Report, Infrastructure Technology Institute, School of Engineering and Applied Science, Northwestern University.

[17] Gholizadeh S., Leman Z. and Baharudin B.T.H.T, (2015), "A Review of The Application of Acoustic Emission Technique in Engineering", Structural Engineering and Mechanics, Vol. 54, No. 6, pp. 1075-1095.

[18] Turkish Standard TS 11634, (1995), "Nondestructive Testing-Guidelines for mounting Piezoelectric Acoustic Emission Sensors", ICS 77.040.20.100

[19] Turkish Standard TS EN 15495, (2008), "Non-destructive testing-Acoustic emission- Examination of metallic pressure equipment during proof testing Zone location of AE sources".

[20] European Standard EN 13554, (2011), “Non-destructive testing - Acoustic emission - General principles”, ICS 19.100.

[21] European Standard EN 13477-1, (2004), "Non-destructive testing - Acoustic emission- Equipment characterization- Part 1: Equipment description”, ICS 19.100.

[22] European Standard EN 13477-2, (2010), "Non-destructive testing-Acoustic emission - Equipment characterization- Part 2: Verification of operating characteristic", ICS 19.100.

[23] ISO/DIS 16148.2, "Gas cylinders- Refillable seamless steel gas cylinders-Acoustic emission examination (AEE) for periodic inspection". 